Presented at the $2 d$ Midwinter Convention of the American Institute of Electrical Engineers,

New York, February 26, 1914, under the aus-

pices of the Electric Power Committee.

Copyright 1914. By A.I.E.E.

\title{
PROBLEMS OF HIGH-TENSION TRANSMISSION LINES
}

REPORT OF SUB-COMMITTEE ON TRANSMISSION

P. W. SOTHMAN, CHAIRMAN

\section{INTRODUCTORY}

T IS not intended that the following article shall completely 1 cover the very broad subject of transmission of electrical energy, but only outline some of the more important problems which have to be considered when building and operating high-voltage lines. Such data as are contained herein have been supplied by the members of the sub-committee with the idea of furnishing a basis for discussion, for it is recognized that the principal value of a paper of this kind lies in the discussion which it may elicit.

Some of the topics of particular interest at this time have been treated in short special articles which are published as appendices to this report and which appear under the names of their respective writers.

\section{Right-OF-WAY}

In sparsely settled countries there is generally no trouble in securing as much land as may be needed for the erection of the transmission and telephone lines, and the only point to bear in mind is the choice of route involving the least constructional difficulties, such as the crossing of mountain ranges and streams or the avoiding of locations which make patrolling and maintenance unduly expensive. If a restricted locality were known to be particularly subject to lightning storms, this would naturally be avoided, if possible.

On the other hand, in districts like the East where the land is already fully occupied and sometimes quite valuable, the rightof-way problem is often not an easy one, and the question arises as to whether it may not be advisable to obtain easements, giving the company the right to erect and maintain its lines across the lands of the owners. Tower lines may even cross fields under cultivation, causing practically no inconvenience to the farmers, who have been known in many cases even to plow and grow grain between the legs of the towers themselves. For 
convenience in patrolling and the making of repairs, the route should, as far as possible, be chosen alongside of highways, regardless of whether the right-of-way is purchased outright or not. The width of right-of-way is an important consideration, as well as the minimum clearances which should be allowed above ground.

There are cases in which it may sometimes be advisable to utilize the right-of-way of an existing steam or electric railway, provided a suitable agreement can be reached between the respective parties. This arrangement has been objected to at different times by laymen because of the alleged danger to the traveling public. That this objection is groundless, we all know, and decisions have been rendered by at least one State Public Service Commission to this effect. Objection to this practise has also been made by the telegraph companies.occupying the same rights-of-way, on account of the interference which may be set up in such circuits because of the proximity of the power lines. By the use of proper care these troubles may be reduced so as to become unimportant, so that this objection also is overcome.

Under this heading may also be included the constructions necessary for the crossings of railways and other circuits. There is at present no generally recognized type of crossing protection, and whatever kinds are used are usually subjects for agreement between the parties concerned. Certain protection from falling wires or cables is desirable, but we feel that the matter has been carried to extremes in many instances. If two power companies adopt elaborate and expensive means for protecting their respective circuits where crossing one another, when an ordinarily substantial construction of the lines themselves would suffice, how can they object if the telephone and telegraph companies, whose lines they have to cross, insist that an equally elaborate protection be installed for their crossings also? This shows the need for an intelligent agreement upon the subject and for a code of rules or specifications, preferably bearing the sanction of the Institute, which will be accepted by all parties. Such specifications should allow a certain latitude in the construction so as not to inflict unnecessary hardships upon small power companies operating at comparatively low voltages, or those located in unsettled districts.

\section{Towers}

The selection of the type of tower depends upon the number of circuits to be carried, line voltage, whether suspension or 
pin type insulators will be used, the physical characteristics of the country through which the line will pass, and also upon the climate. It is generally agreed that the square or four-legged tower is more efficient in the use of material than the threelegged tower and the latter is seldom seen nowadays in new work. The flexible type of tower has also been used to some extent with good results, but it is necessary to place rigid towers at frequent intervals along the line to act as stays, from which the flexible towers are more or less supported by the overhead ground wires and also by the power cables when pin insulators are employed. It is too early to say what success will attend the flexible tower when used in connection with long suspension insulator strings, and until more data are available upon the subject it is advisable to proceed with caution when considering the adoption of this construction.

Where suspension insulators are employed, it has been found that it is not good practise to place two or more conductors in a vertical plane, especially where snow and ice are liable to collect upon the cables. When this load breaks away it very seldom does so uniformly and the cables are in great danger of coming into contact. This phenomenon has been quite fully treated in a recent paper. It might be added that it has been observed in the East that ice seems to collect to a greater extent at the centres of the spans than near the towers, which should be taken into consideration.

The method of calculation of tower designs should be standardized, and the constants for such materials as copper, aluminum and steel used for conductors should be taken at some acceptable figure such as $30,000 \mathrm{lb}$. for copper, and 14,000 1b. for aluminum, as representing the elastic limit of the material. The design should be calculated so that when the loads estimated are all on, the structure will be stressed to the elastic limit. The factor of safety is therefore in assuming excess loads over those which are known to be liable to happen.

Ordinarily towers should not be calculated, but they should be specified to stand certain loadings, and should be tested for these figures.

Foundations. It is very important in the use of rigid towers to see that the foundations on which the tower stands are all at the same height, and therefore, it should be specified that the foundations of the tower should have their tops within $1 / 10$ of an inch of the same height. 
Minimum Thickness of Material. In the construction of towers no material should be used less than $3 / 16$ in. $(4.7 \mathrm{~mm}$.) in thickness.

Bolted Connections. It is recommended that the minimum number of bolts in any connection be not less than two.

Strength of Members. It should be kept in mind in the design of the towers that men are likely to climb up and down the towers on the angles, and therefore, one of the limiting conditions is to see that no members are used which would be bent by the weight of a man in so climbing a tower.

Movement of Wires. It would seem advisable to increase the customary figure of $45 \mathrm{deg}$. used for angle of deflection of the insulators to $55 \mathrm{deg}$. or $60 \mathrm{deg}$. from vertical, under the worst wind conditions.

The effect of ice and sleet should be considered, and this from the point of view of non-uniform loading. The structure should be so designed as to permit the loading of one span with the two adjacent spans not loaded, and still have sufficient clearance between all the wires so that under these conditions there would not be probable contact due to wind conditions.

Amount of Sleet. Not less than $\frac{3}{4}$ in. $(19 \mathrm{~mm}$.) of sleet or ice for the northeastern part of the United States and the eastern part of Canada should be allowed for.

Wind Load. The wind load is heaviest at times of sleet, and it should be recognized that the sleet does not form uniformly around the wires, but that the section of the ice is more or less elliptical.

Wind Pressure. It would seem advisable to increase the amount of wind pressure for the eastern part of Canada and the United States to about $15 \mathrm{lb}$. $(6.8 \mathrm{~kg}$.) pressure per sq. $\mathrm{ft}$. ( 0.09 sq. m.) on the round surface.

The usual method of erecting towers is to assemble them lying on the ground and then tilt them into place, which is apt to induce faults in them, hence it is very necessary that a careful inspection be made of them after erection, with a view to tightening up the bolts and examining the various members to see whether they are distorted.

In many cases towers have been provided with insufficient means for supporting and firmly holding the ground cables. The ground cable clamps should be quite long and have not less than four bolts so that the cables cannot possibly slip, allowing them to sag down in contact with the power conductors. 
Galvanizing and Painting. From reports received from various quarters it appears that the galvanizing of steel towers is generally preferred to painting. Probably the manufacturers themselves differ more on this point than the users of towers. One manufacturer advocates painting because of the simplicity obtained in erection by having the sides of the towers assembled complete and riveted in the shops, only the cross members requiring to be bolted together in the field. Large pieces assembled in this manner cannot well be galvanized and painting must be resorted to.

Paint affords a good protection if the structures are periodically gone over and carefully scraped and cleaned before the paint is applied. It is very difficult, however, to reach all small interstices and pockets and these are the places where rust is most apt to occur. Superficial inspection frequently will not disclose rusting which may be occurring beneath the paint coating. There is no doubt that periodical repainting is more neglected than otherwise.

Galvanizing, on the other hand, practically eliminates worry and expense for maintenance, as it is electro-positive to iron. The galvanized coating has two functions, to perform. In the first place, it is designed to keep the surface of the steel from coming into contact with water and the atmosphere, and secondly, it.protects the iron whenever water and oxygen finally succeed in breaking through.

If the galvanizing is properly done, it may be relied upon to be in good condition at the expiration of 12 or 15 years, whereas painting cannot be depended upon much longer than two or three years, especially where the atmosphere contains sulphur or other fumes.

Footings extending into the earth may be galvanized with good success in most soils, although there are earths where asphaltum paint coating is more durable. In cases where extreme acidity or electrolytic action is expected in the soil, it is more economical in the long run to provide a concrete footing thoroughly encasing the steel.

\section{CONDUCTORS}

The relative merits of copper and aluminum conductors have been discussed quite often and it is not our intention to open the subject again at this time. A thorough understanding of the different qualities of the two metals should be had by engineers designing transmission lines, especially where suspension 
type insulators are considered, in order that advantage can be taken of these qualities. There are certainly places where aluminum should not be used for power conductors, but on the other hand, there are quite often cases where it might be used to better advantage than copper.

Experience has shown that hard-drawn copper cables should not have hemp centers, for an action partly chemical and partly mechanical is set up which sooner or later weakens the strands and causes the cable to part.

In order to secure a greater strength and also partly to add weight to the cable a steel core has been inserted in some of the aluminum cables recently manufactured. While it is claimed by the makers that such cables are as durable as the ordinary aluminum cables and free from electrolytic corrosion, conclusive proof upon this is still lacking. It is understood that steel cores in aluminum cables are not considered satisfactory by English cable manufacturers.

For long spans where great strength is required, wires and cables made of steel having a coating of copper (copper-clad steel) are available, which give very good results. These wires are still too high in cost to be used generally for power conductors. They are coming into use to a certain extent, however, for telephone and telegraph lines.

In passing, it may not be out of the way to remark that there are several formulas in existence, all more or less tedious in their application, for the calculation of cable sags, taking into account temperature changes as well as spans and tensions. The majority of these are adaptations of the parabola formula and will give sufficiently accurate results so long as the spans and sags are moderate. We would suggest that some simple method, such as a set of curves, be evolved, based preferably on the catenary, from which the sags may be quickly and accurately determined for all possible conditions.

Ground Wires. It is generally agreed that overhead ground wires are beneficial as a protection against lightning. Just how much protection is actually afforded, however, is still a mooted point. A report given below, on this subject, from one of the large companies in the West, well illustrates the feelings of a majority of operating engineers.

This company has about 450 miles $(724 \mathrm{~km}$.) of 60,000 -volt pole line without overhead ground wires, and about 100 miles $(160 \mathrm{~km}$.) with the overhead ground wire. 
In the case of one particular branch about 42 miles $(67.5 \mathrm{~km}$.) long, running northerly, we feel that we have had reliable and conclusive evidence that the overhead ground wire does protect. We have had a number of thunder storms cross this line at right angles, and while lightning would sometimes cause the automatic oil switches to open at the power station, yet no real damage occurred to either the line conductor or insulators, neither were the poles split by the lightning discharges. In other words, service could be re-established at once. On the other hand, these same storms would sometimes destroy pin type insulators and pole tops, on lines not protected with the overhead ground wire, and the general opinion has therefore been formed that the overhead ground wire does protect against material of the line being destroyed. However, we do not have either the number or severity of lightning storms that a large portion of the states do. We have, on all new work permitting the expense, equipped our lines with the overhead ground wires.

We might add, however, that the testimony is not altogether in one direction. While we have had very good direct evidence of the usefulness of the ground wire in one line, on another line we have had several insulators shattered, notwithstanding two ground wires on the top of a steel tower transmission line. These troubles, however, have been due to what we are quite sure have been direct strokes of lightning.

\section{INSULATORS}

Reports received from various parts of the country indicate that the suspension insulator as usually manufactured, in the disk type with metal caps and pin, is quite satisfactory when new, accomplishing the purpose for which it is intended, up to voltages of at least 150,000 . The fly in the ointment, however, is that after they have been a year or two in service, failures begin to occur, and as time goes on a large number of the sections have to be replaced. To insure steady service on the lines the insulators have to be inspected at frequent intervals to weed out any that have become faulty. This trouble is not confined to any make of insulator nor to any section of the country. Extracts from reports from several companies are given herewith which will serve to show how prevalent the difficulty is and the means employed for inspection. The first report deals with conditions encountered on the lines of two or three companies in the South.

The Carolinas experienced very severe lightning during the past summer. Following repeated failures of insulators in a limited portion of a certain line, under the writer's observation, it was believed that there might exist insulators which were punctured, but of which no external signs were visible.

The line in question consisted of a single and double circuit steel tower line, equipped with suspension insulators and one ground wire. 
It was accordingly determined to see if it was possible to locate any such punctured insulators by means of a megger.

A megger was secured, giving 500 volts, and reading 1000 megohms; The method of procedure was as follows:

On a single-circuit tower line a party was organized consisting of engineer in charge of megger, and six linemen, working in pairs. One pair would proceed to ground the line on a certain tower and hold the leads of the megger, which consist of about $100 \mathrm{ft}$. $(30.4 \mathrm{~m}$.) of standard lamp cord, to the individual disks in the strings of insulators, by means of two wood handles. The readings would then be taken, whereupon the megger would be taken to the next tower, on which another pair of men were ready to go through the same procedure. With this arrangement about four towers per hour could be tested, each tower being provided with eighteen disks.

On a double-circuit line about 26 towers were covered in ten hours.

The following results were obtained:

On a total of 2100 disks under observation, 14 of this number were found defective.

Twelve disks had defects invisible from the ground, and in two disks the defects were visible from the ground.

Of the twelve invisible from the ground, two of these could be noted as defective from the tower, four could be detected by very close inspection, after taking down, and six showed absolutely no defect.

One of these disks, the defect of which was entirely invisible, measured 300 megohms, two measured 250 megohms, and the balance were less than five megohms, which was the lowest point on the scale. Good disks were considerably over 1000 megohms.

\section{Insulator failures with reference to their location on line, and relation to ground wire:}

On a $100-\mathrm{kv}$. line, protected by ground wire, of a total of 94 failures of disks, it was noted that 28 were on the top wire, 25 on the middle wire, and 40 on the bottom wire.

Insulator failures in reference to steel towers vs. wood poles:

Insulator failures were compared on the following basis:

$100-\mathrm{kv}$. tower line............. 35,770 disks

Failures...................... 94 “

(Wires arranged vertically, single and double circuit, one ground wire)

$60-\mathrm{kv}$. tower lines................ 2440 disks

Failures................... 4 "

(Wires arranged horizontally, single circuit, one ground wire)

60-kv. wood pole line............ 14,850 disks

Failures.................. 4 "

(Wires arranged on right triangle, single circuit, one ground wire) 60-kv. wood pole line, using pin type insulators: 5718 insulators Failures........................ 1 insulator

(Wires arranged in right triangle, single circuit, no ground wire.)

The suspension disks are 10-in. $(25.4 \mathrm{~cm}$.) corrugated, single piece porcelain. The pin types are four-part, $14 \mathrm{in.}(35.5 \mathrm{~cm}$.) diameter, 12 in. $(31.9 \mathrm{~cm}$.) high.

In connection with these failures it should be noted that the $100-\mathrm{kv}$. 
line is equipped with six disks per string and the operating voltage is between 95 and $100 \mathrm{kv}$. The $60-\mathrm{kv}$. lines have three disks per string and operate at from 60 to $65 \mathrm{kv}$. The pin type insulators operate at 60 to $62 \mathrm{kv}$.

Probably one-third of the failures on the $100-\mathrm{kv}$. line occurred when the line was dead and the two ends of the same grounded. Of the four failures, on the $60-\mathrm{kv}$. wood pole line, using suspension insulators. three of these occurred while the line was temporarily operating at 22,000 volts. The pin insulator failure occurred while the line was dead and all three wires grounded at one end. The question arises, after considering these failures. whether there is any use in having more disks than are required to give a reasonable factor of safety on insulators, and also whether wood crossarms on steel towers should not be seriously considered.

Next follows a report from a California company.

Regarding the experience of the Southern California Edison Company with high-tension transmission lines, this company built a transmission line of 70,000 volts and about 120 miles $(193 \mathrm{~km}$.) long.

The towers are of steel, and a pin type insulator was used, being 18 in. $(45.6 \mathrm{~cm}$.$) in diameter. These insulators were carefully tested out in$ the factories in the East, and were of three different makes.

These insulators gave absolutely no trouble for a period of at least one year, and the only line trouble experienced was due to eagles grounding the wire to the steel towers. However, after the second year had passed we began to experience considerable puncturing of insulators, and a careful inspection disclosed many insulators which were honeycombed with minute cracks. The line was very carefully gone over, each insulator being struck with a piece of hickory wood; this being the method used in testing fine porcelain ware in the china shops. All defective insulators were carefully culled, every one not ringing true being at once removed. We sometimes found indications of cracks on the rim of the insulator, but as a rule on one or the other of the petticoats. During the past five years, I have brought this matter energetically to the attention of the porcelain manufacturers, and have always insisted that the porcelain of the insulator shows an apparent aging, the cause of which we have been unable as yet to determine. This may be due to the extreme changes of temperature, to the continual vibrations of the wire, or perhaps a combination of the two; at any rate the aging of these insulators is going on with increasing rapidity, and every inspection of the line means the finding of hundreds of defective insulators which were in good shape the year previous.

In changing these insulators over (which work is going on at present) all are being replaced, both good and bad, with the suspension type. We have endeavored to use a few of these large 18 -in. $(45.6 \mathrm{~cm}$.) insulators on some of our local 33,000 -volt lines, with the idea that they would be serviceable in sections where the salt from the sea rapidly encrusts them; but even at this low potential we have had many of them break down electrically, showing that the insulators which originally stood the test for 100,000 volts were rapidly becoming wholly unfit for any of the highpotential work.

Our experience with the suspension type insulator has been too limited 
to warrant us in giving an opinion as to their superiority over the pin type, but on our 60,000-volt line, four insulators in series, extending from Long Beach to Colton, a distance of approximately 80 miles $(128.7 \mathrm{~km}$.), we have discovered a great many broken insulators; especially when used as strain insulators. These were evidently broken by extra mechanical strain, and showed no exterior indication of injury. We, however, are watching this very closely, and have gone to the expense of changing the sets of insulators, taking the old ones back to our laboratory for test. As stated above, there appears to be a continual aging of all porcelain insulators going on, and they seem to be short-lived. Whether this is due to the combination of electrical and mechanical strain, I am unable as yet to say. lines.

The following report by another engineer is along the same

Experiments in the method of eliminating defective insulator sections by tests of insulation resistance with a megger have been conducted on the 100-kv. lines of the Yadkin River Power Company in North Carolina and upon new insulators in Utah intended for erection on the $130-\mathrm{kv}$. lines of the Utah Power \& Light Company.

The Yadkin River Power Company operates 96 miles $(154.4 \mathrm{~km}$.) of double-circuit $100-\mathrm{kv}$. line from the Blewett Falls generating station to Raleigh and connecting through to the Southern Power Company at Durham, and also a 56 -mile $(90.1 \mathrm{~km}$.) single-circuit line from Blewett Falls to Lumberton. This latter line is supported in part by singlecircuit towers and in part by double-circuit towers carrying also a $22-\mathrm{kv}$. circuit. The conductor is three-strand No. 1 B. \& S. copper. There is one overhead grounded cable and the insulators consist of six 10-in. $(25.4 \mathrm{~cm}$.) disks of the usual type. This line traverses a district subject to lightning storms of unusual and even extraordinary severity. During the past summer, the first lightning season of the line's service, there have been numerous cases of insulator trouble. Nearly all of the trouble has been experienced over a short section of about six miles $(9.6 \mathrm{~km}$.) length. The section is in open country and contains no angles or special features of construction, and no explanation of its especial susceptibility is obvious except that the storms appear to be of greatest severity in this vicinity. Failures have occurred usually on insulators supporting the top or the bottom conductor. The top conductor changes to the bottom at a transposition point in this trouble section.

The failures have been almost all of the same character; a disk will be punctured through the head, inside of the cap, the puncturing will be accompanied by an explosion which will blow considerable porcelain from the cap, causing the disk to separate and allowing the line to drop. The disk usually affected is the lowest of the string.

The load at Lumberton is mainly cotton mill power and no power is taken on Saturday afternoon and Sunday. On Saturday and Sunday, August 16 and 17, megger tests were made of all of the disks on 28 towers, covering between three and four miles of the section which has been experiencing trouble.

On the 28 towers were 94 strings of six disks each, or 564 disks. The disks were tested one at a time. Thirteen disks or 2.3 per cent were 
found to be defective, the 13 disks occurring in 12 strings. Of the 13 punctured disks, two would have been apparent from the ground, since the disks were broken; six could have been discovered by close inspection after climbing the tower, since there were cracks in the metal insulator cap; three could not have been observed from the tower but would be apparent after taking down the insulator; and in two cases the disks did not show any visible evidence of having been punctured, although the megger showed them to have no insulation value.

Although these tests were on a very small scale and there has been no subsequent opportunity for continuation of them, yet they indicate that frequently a string of insulators will fail gradually, one disk at a time, and that a considerable measure of protection may be secured by periodic elimination tests with a megger, provided lines may be taken from service for the tests.

In Utah experimental tests have just been started on insulators not yet erected. The first reported test was as follows:

A. 40010 -in. (25.4-cm.) disks were tested and found good.

B. 10010 -in. (25.4-cm.) disks of another make were tested and found good.

C. 264 pillar insulators each consisting of three 10 -in. $(25.4 \mathrm{~cm}$.) disks were tested; 26 insulators contained one bad disk each and two contained two bad disks each, a total of 12 per cent bad insulators or 4 per cent bad disks.

The insulation resistance of the defective disks ranged from 550 megohms to a value below the scale of the megger, which was one megohm.

D. 12 pillar insulators of another make, each consisting of eight 14-in. (35.5-cm.) disks, were tested and one disk found bad. The insulation resistance of this disk was about 25 megohms.

The defective insulators had been subjected to a factory high-potential test before shipment.

Three of the low-resistance 10 -in. $(25.4-\mathrm{cm}$.$) disks in the pillar in-$ sulators mentioned above were subjected to a high-potential test and all failed, although at such voltage values as to make it seem possible that some would have stood up for a considerable period in service before actually puncturing. In the case of two others of the low-resistance disks, the metal caps were drilled off, but no cracks or visible defects were found. In general, it seems probable that clean insulators which have the low values of insulation resistance noted above will not stand high-potential service, owing-to the local heating which would inevitably result.

These Utah tests are being continued with a view to determining the advisability of making such tests of all of the insulators on hand before putting them into service.

It is planned to incorporate a megger test in the specifications for all future insulator orders.

At voltages around 110,000 and even somewhat higher, there seems to be no reason for providing protection for the end units of suspension insulator strings to equalize the voltage gradients over the whole. There will doubtless come a time, with higher 
voltages, when such protection will be needed, and experiments have been made which demonstrate the efficiency of end shields for this purpose. These shields act simply as electrodes for equalizing the electrostatic field in the region occupied by the insulators. Shields should present smoothly rounded surfaces and edges and need be no greater than 12 to 14 in. (30.4 to $35.4 \mathrm{~cm}$.) in diameter to produce good results. With these shields may be mounted arcing rings or tips to keep arcs away from the insulators, as found necessary.

\section{Clamps and Fittings}

There are several types of clamps on the market intended to secure the line conductors to suspension and strain type insulators. These all perform this function very well insofar as they do not allow the conductor to slip. Some are so severe, however, that the cable is mashed and unfit for taking strains if the sags ever have to be readjusted, by no means an uncommon occurrence. Practically none of the clamps are designed with smooth outlines or with an idea of avoiding more or less sharp projections which cause static discharges at the higher voltages and which concentrate the electrostatic field in that vicinity.

\section{Notes on Station Apparatus}

Rapid improvement has been made in the design and construction of transformers since the advent of the higher voltages. It was a comparatively simple matter to build a transformer for 60,000 volts which would stand up under all manner of severe service without ever giving any trouble, even when used with a large generating capacity back of it. Transformers built along the same general lines with more insulation were then tried at 110,000 volts, but trouble developed almost at once, sometimes through the short-circuiting between turns of the windings or else at tap points, and quite often by the distortion of the coils under short-circuit conditions. It was then recognized that because of their different physical constants, the higher voltage transformers were, so to speak, much more susceptible to line disturbances such as switching, etc., than those for lower voltage, and the designs have been changed accordingly, much attention being given especially to the bracing of the coils. The greatly improved results which have been obtained since these changes have been carried out, testify to the soundness of the principle of strengthening apparatus against failure rather than the spending of large sums on protective devices of various kinds. 
An important problem for distribution companies serving sparsely settled districts, especially those in the West, is that of securing small high-voltage transformers, three-phase or single-phase, which will stand up under the line switching, surges, etc., which occur in ordinary operation of a large hightension system. The companies must generally reach out for all possible load wherever it may be, and it is of prime importance that this subject of small high-tension transformers should receive the greatest possible consideration, as the services usually secured by their use pay the highest price for energy, making it possible for any company to extend its lines to be ready for the business as the country develops. Such transformers only, will make it possible to serve the farming community, which, it is claimed by some, offers the most attractive income now in view for operating companies, because of the fact that once the farmer is connected to the lines, he will remain a customer with increasing energy consumption, with good load factors, and furthermore, the general expense of service, such as collections, moving meters, etc., is very much reduced with this class of service, in contrast to the floating population of a great many cities.

Oil circuit breakers are becoming more reliable for high potentials and heavy service, but it is still unwise to attempt to rupture short circuits close to the generators when their combined normal capacity is much greater than $50,000 \mathrm{kw}$.

While it is generally believed that the electrolytic lightning arresters, as at present developed, are the best in their line that the art affords, it is still quite difficult to make any definite qualitative statements in respect to the protection they actually afford against lightning or other disturbances. Certainly no one would care to take the responsibility of operating stations without arresters, for they are considered to be a form of insurance against trouble; but it would be desirable to have more light on the subject.

\section{Interferences with Telephone and Telegraph Lines}

This is a subject which has been given but little attention, although the problem is a very important one. Nearby telephone and telegraph lines are sometimes made inoperative when any disturbance exists on the transmission line.

A good part of the trouble of the telephone service is due to insufficient insulation. Some of the lines, before long-distance 
transmission was inaugurated, ran through and touched the branches of tree tops, which caused leakage in wet weather, and hence unbalanced the wires.

With the troubles due to poor insulation overcome and the transmission line well balanced, no further trouble was encountered except at times of disturbance or interruption on the transmission line. With grounded systems this resulted in the burning out of telegraph relays and blowing fuses on the telephones.

A much more difficult matter to deal with is the making of the transmission company's own private telephone to operate at all times. Usually the telephone line is needed the most at times of trouble and this is just the time when it is out of service, having been put out of commission by the trouble itself.

When providing protection for a recent telephone line paralleling a high-voltage system for a distance of some 300 miles (482.8 $\mathrm{km}$.), it was found that there is no protective apparatus on the market capable of handling the large induced currents which are always present on such lines.

Thus the apparatus had to be built, and was of a very substantial character. The basic principle which was worked upon was to make the line subject, in the first place, to as little trouble as possible by carefully insulating and balancing it with respect to the transmission line circuits. This meant that transpositions had to be placed at frequent intervals. Furthermore, no twigs or other objects were allowed to come into contact with the wire. The usual grounding coils, but designed specially for this purpose, were cut in at each station. By these means alone the line was rendered quiet, even though within $60 \mathrm{ft} .(18.2 \mathrm{~m}$.) of the highvoltage wires, and conversation could be carried on over a distance of 125 miles $(201 \mathrm{~km}$.) with greater satisfaction than over the paralleling commercial circuits. Much heavier fuses were used, for it was not permissible to have them blow out when the circuits were needed most. Discharge gaps were provided, some of these being in vacuum, which gave very good results. The other protection consisted of condensers and choke coils tor absorbing the smaller disturbances which would make conversation more or less unsatisfactory. It must not be understood, however, that any or all of these means can be guaranteed to produce a quiet working line, for each case must be studied by itself and methods adopted to meet the conditions. 


\section{APPENDIX I-DETERIORATION OF PORCELAIN INSULATORS IN SERVICE}

BY J. A. BRUNDIGE

While it has been recognized practically since the inception of the electrical art that the commoner insulating materials, such as rubber and compound treated fabrics, are subject to more or less rapid destruction when under the influence of continued electrical stress, the more solid insulating bodies, like glass and porcelain, were looked upon as being permanent in their characteristics and it was considered that they could be relied upon indefinitely to perform their functions. This idea in the minds of engineers has persistently held, even though a few pioneers a number of years ago suggested that it was not impossible that glass and porcelain might be subject to a molecular fatigue when acted upon by electrical forces for long periods, similar to that exhibited by metals under repeated mechanical stresses. Now it is safe to assume that the majority of operating engineers, having to deal with higher voltage transmission lines, have had experiences which lead them to believe in the theory of electrical fatigue in porcelain. Whether this comes about solely through the continued application of the normal operating voltage or whether it is due to the transient overvoltages which are unavoidable on any line, is hard to say, but the existing evidence points to the latter conclusion.

It must not be understood that all or even the greater portion of the failures experienced with suspension type insulators are due to molecular deterioration of the porcelain. A large number of the failures have been traceable to improper design of the insulator parts or to an unsuitable porcelain body.

It has been the experience of a number of transmission companies to have practically no insulator trouble for the first couple of years of operation; then the insulators began to fail in increasingly greater numbers, for no apparent reason. Closer examination, however, sometimes revealed the fact that minute checks had formed all over the surface of the porcelain, and that the failure had been due to a crack extending clear through the shell. This behavior of the porcelain has not been confined to any kind or type of insulator nor to any one manufacturer's product.

The principal requisites for a good porcelain for high-voltage insulators, are high dielectric strength and mechanical toughness. These two qualities are somewhat opposed to each other 
in the actual manufacture, for when a high dielectric strength is obtained, the porcelain is apt to be brittle like glass. It is possible, however, to arrive at mixtures which exhibit both properties to a marked extent when the firing has been properly done, although it is regrettable that some so-called high-voltage porcelains appear to be lacking in both of these properties.

This can be better understood when it is learned that the mixtures used by two promin ent manufacturers, each putting out a product which is accepted as reasonably good, vary greatly in the proportion of ingredients employed. While the felspar contents of the two mixtures are of the same order, one has twice as much flint as the other, and the quantities of ball clay and china clay vary as much as three to one. Yet the different manufacturers regard their mixing formulas as trade secrets, and the proportions are religiously followed down to tenths of one per cent. This latter is doubtless done for the sake of uniformity of product, which is important, but until the mixtures more nearly approach a recognized standard, it appears that more or less trouble may be expected with hightension insulators.

Doubtless, the factor having more to do with the failure of insulators than the porcelain body is the design; or in other words, not only must the electrical characteristics of the insulator, such as puncturing and flash-over values, both of which are highly important, be considered, but also the size and shape of the parts as well. With certain pin type insulators, especially those mounted on metal pins, cracks have been observed in quite a number of the petticoats. These were evidently expansion effects due to temperature changes. The same effects have been noticed to a greater extent with the suspension type insulators provided with metal caps and pins. We have here porcelain, cement and iron assembled together, the coefficients of temperature expansion of the three being quite dissimilar. In this latitude the temperature variation between summer and winter days is well in excess of $100 \mathrm{deg}$. fahr., and it can be appreciated that enormous internal strains must be set up inside of the caps. The porcelain being the least able to withstand these forces, is the part that suffers and cracks, with the attendant electrical punctures ensuing. In the case of an insulator designed for high mechanical strength in tension, which necessarily means a rather high cap with correspondingly long pin, the temperature changes cause a marked var- 
iation in the length of the pin which is in contact with the porcelain through means of a layer of cement for a distance of sometimes $2 \frac{1}{2}$ to 3 in. ( 6.3 to $7.2 \mathrm{~cm}$.) along its length. The great strain to which the porcelain is subjected is then apt to produce cracks perpendicular to the axis of the pin, which has actually been found to be the case in a large number of instances. These cracks, however, are mostly very minute and can hardly be detected by the eye if the cap and the cement have been carefully removed. A line of ink drawn over the surface of the porcelain, however, will nearly always disclose the cracks, as the ink will be drawn along them by capillary action.

The method of failure of suspension insulators with metal caps and pins is often quite characteristic. Cracks develop at some point inside the cap, and when the current leakage through them is sufficient, a path is fused through the porcelain by the intense heat generated. If the heating takes place relatively slowly, a hole is apt to be fused through the cap, through which gases and melted porcelain are forcibly expelled, but the insulator usually holds together and continues to support the cable. With a large amount of power back of the break, which may act in the nature of a short circuit inside the insulator, caps have been known actually to explode, in which event the line conductor is allowed to fall. Before the burning of the caps can take place, it is necessary that several of the units of an insulator string be bad, and instances have been observed where all the caps of ten-unit insulators have been so affected. With the better methods for locating cracks and faults as soon as they have developed, such as the high-range megger, the pyrotechnic displays above described have become fewer.

Because of several instances of trouble of this character having recently been observed in connection with suspension type insulators, some engineers have been led to believe that they are unsuccessful, which conclusion is wholly unwarranted.

The high-range megger has proved to be an extremely useful instrument for the locating of insulator faults undiscoverable so far as ordinary means of inspection are concerned. Tests made on a large number of units later checked up by tests with a high-tension transformer, have shown that the megger can be absolutely depended upon if reasonable care is used to see that there is no leakage in the conducting leads. To show the sensitiveness of the megger, the two electrodes can be placed within $\frac{1}{4}$ in. $(6.3 \mathrm{~mm}$.) of each other on a glazed porcelain sur- 
face or upon a fractured surface where there is no glaze and the reading will be practically infinity. By blowing the breath upon this surface even when the porcelain is at a moderately high temperature, the moisture so deposited will be sufficient to give a comparatively low reading on the needle. When a crack occurs in the porcelain up inside the cap there is always sufficient moisture present in the cement to give an indication on the needle, which need not be confounded with surface leakage, if the insulator is at all reasonably clean. If the insulators are so dirty that surface leakage is marked, they should be cleaned before the megger test. Certain insulators may give a reading of from 40 to 100 megohms, and if later tested with a high-tension transformer they will not fail immediately upon the application of voltage, but may hold up until 30,000 , 50,000 or even 60,000 volts is reached before puncturing. Those which show a zero reading on the megger will stand no voltage from the testing transformer.

An interesting experiment was recently made by immersing a batch of insulators in water at ordinary temperature and slowly bringing them up to the boiling point. Twenty insulators, some two or three years old, were tested in this manner and every one was found to be ruined by the time boiling point was reached. These were from two different manufacturers, one of whom has previously delivered batches of insulators where bringing them to the boiling point of water was one of the routine requirements before the insulators left the factory. Other similar tests made on new insulators of the same design did not produce failure, except in a few units. The probable explanation of this is that in the new insulators the cement had not yet attained its ultimate hardness, and allowed the expansion to take place in the pin without cracking the porcelain.

The data at hand upon insulator failures are unfortunately very incomplete, and until these are collected and have been studied, all designs brought forward must necessarily be lacking in some respect. Enough is already known, however, to indicate the general direction which the new designs will follow, and it may be confidently predicted that the troubles experienced will be materially lessened in the immediate future. 


\section{APPENDIX II-RADIUS OF INFLUENCE OF A DIRECT LIGHTNING STROKE}

BY L. C. NICHOLSON

A lightning stroke to earth at some point adjacent to a hightension transmission line induces voltages and frequencies in the transmission conductors of sufficient magnitude to affect the insulation of the line, causing either spill-overs or punctures of insulators. The question often arises as to how near the line lightning can strike without affecting its operation. The answer to this question can never be definite, since not only do transmission lines vary in degree of both insulation and lightning protection, but the character and severity of lightning strokes undoubtedly vary between wide limits. General atmospheric electrostatic conditions also have an effect.

Through continued personal inquiry it is possible to arrive at a general estimate concerning the radius of influence of a direct lightning stroke. By noting objects which have been struck by lightning adjacent to transmission lines and comparing the operation of the line at the time the object was probably struck, an opinion can be arrived at, which is applicable to a particular transmission line located in a given lightning belt. Such an opinion undoubtedly would have to be modified considerably to apply to transmission lines of different insulation characteristics and lightning protection and exposure.

Observation and inquiry lead to the following general conclusions on this subject.

1. It is doubtful if any degree of insulation in use at present, with or without the ordinary protective measures, will withstand the effect of a direct stroke of lightning on the line. In such a case the electromechanical forces acting on the porcelain are very high, usually causing insulators practically to explode. It is not unusual in such cases to find insulators shattered into small fragments, many of which are thrown as far as $100 \mathrm{ft}$. $(30.4 \mathrm{~m}$.) from the line. Furthermore, a direct stroke usually envelopes all the conductors of a line and sometimes envelopes several lines located relatively close together. This would indicate that the area of the stroke itself is large, or that it has numerous prongs. Observation of burn marks on conductors which were struck when there was no power on the line indicate by their distribution and extent that the diameter of the stroke was approximately $20 \mathrm{ft}$. $(6 \mathrm{~m}$.) Such being the case it is not surprising that one or more overhead ground wires cannot always intercept direct strokes. 
2. Induced effects from strokes at some distance from the line may, on medium-voltage lines, be of sufficient magnitude to cause flash-over or puncture of insulators. Extended observation of the operation of 60,000 -volt pin type insulators, unprotected by overhead wires, leads to the estimate that the radial influence of direct strokes is rarely in excess of $2000 \mathrm{ft}$. $(609 \mathrm{~m}$.) and may be less than $100 \mathrm{ft} .(30.4 \mathrm{~m}$.). These are rather wide limits, but the most definite evidence available indicates their probability. It appears that strokes of great severity, $2000 \mathrm{ft}$. (609 m.), and more in extreme cases, from the line, produce disturbances of operation, while strokes of less severity may occur at $100 \mathrm{ft}$. $(30.4 \mathrm{~m}$.) from the line without producing such results. These last are, however, in our opinion, rare, and a stroke at less than $2000 \mathrm{ft}$. $(609 \mathrm{~m}$.) from the line is apt to cause trouble.

In more highly insulated lines the danger zone apparently decreases substantially, and in the most highly insulated circuits at present in operation it is probable that the large majority of induced effects are insulated and protected against, leaving only direct strokes on the line itself to be taken.

Careful numerical tabulation of lightning effects indicates that direct strokes on the line constitute approximately 10 per cent of all lightning disturbances on 60,000-volt pin type circuits located in New York State.

\section{APPENDIX III-TRANSMISSION LINE PROBLEMS IN THE WEST}

BY P. M. DOWNING

The different power companies operating on the Pacific Coast have done a great deal in the way of pioneer work in the transmission of power over long distances at high voltages. This was due, to a considerable extent, to the fact that there is an abundance of water available for the hydroelectric generation of power, and also to the fact that the cost of fuel is very high as compared with that further east.

The first long-distance transmission to be put into successful operation on this coast, if not the first in the United States, was that of the San Antonio Light \& Power Company in southern California, at what is known as their Pomona plant. This transmission was for a distance of 30 miles $(48.2 \mathrm{~km}$.) at 10,000 volts. 
Transformers were at that time not manufactured for such high voltages, and it was necessary to connect in series ten 1000 -volt transformers for stepping up. The low-tension windings were connected in multiple.

The first polyphase installation was made in 1893, at Mill Creek, and furnished power to the city of Redlands.

The success of these undertakings gave a great impetus to the hydroelectric industry, and inside the next five or six years, there were several different companies operating at voltages as high as 60,000 .

The climatic conditions of the Pacific Coast, and particularly of California, are most favorable to the operation of high-voltage lines. Except in the higher mountain districts, there is practically no snow to contend with, and there are but very few places where lightning ever causes any trouble. Some operating companies have installed lightning arrester equipment, but it is not common practise to do so. The well-known horn gap arrester, one side of which is connected directly to ground without resistance, has in many instances been used to advantage, more as a voltage-limiting device than as a lightning arrester. These have proved quite satisfactory for this work. Ground wires strung above the line wires have been used to some extent, but there is so little trouble from lightning that engineers have never been able to decide as to whether or not there is any advantage in using them.

Very seldom, if ever, is it possible to find where an insulator has been punctured due to lightning. This is, possibly, due to the fact that the high voltage dissipates itself over the surface of the insulators. Many instances are known where lightning striking the line has burned off one or more wires between poles, and gone to ground without in any way damaging the insulators, and only slightly damaging the wood poles.

The greatest trouble on lines using the ordinary four-part, 14 -in. $(35.5 \mathrm{~cm}$.) pin type insulators at voltages around 60,000 is that due to leakage over the insulator. The climate of this coast is peculiar in that there are two seasons, one being dry and lasting for six months, the other being wet. During the dry season, and particularly in the sections near the coast, dust and salt fog accumulates on the insulators to such an extent that leakage eventually burns off the pole, and sometimes the line wires, without damaging the insulators.

Different ways of overcoming this trouble have been tried. 
Cleaning the insulators does some good, but does not entirely eliminate the trouble. After the first heavy rains come on in the early winter, the insulators are washed off and less trouble is experienced during the rainy season than at other times.

Ungrounded metal pins connected together electrically give very much less trouble than where they are not so connected, or where wood pins are used. Grounding the pins has been tried with unsatisfactory results because of arcing over the insulator. When once so established the arc will hold until the voltage drops.

The regulation of voltages on a high-tension network is not always an easy problem. No one particular point can be selected at which voltage can be kept constant, but it is necessary to keep it as nearly uniform as possible over the entire system. This is accomplished by the use of synchronous condensers located at the more important distributing centers.

These condenser regulators can be made automatic by using contact-making voltmeters, relay switches and motors to control the field rheostats; in other words, by the use of auxiliaries similar in every respect to those used in connection with the well known automatic induction regulator. A number of such installations have been in satisfactory operation for several years.

The first high-voltage oil switches were constructed and put into operation in California. The same general type and design that was originally selected as being suitable for 40,000 volts is, with slight modifications, still being used on 110,000 volt lines. In this particular switch the circuit is opened at two or four points, depending on the voltage and load carried. The contacts are made by rotating blades moving in a horizontal plane. The separate oil containers for each leg of the circuit are insulated from each other and from the ground by means of properly designed porcelain bushings or insulators.

Another very successful design of switch for the same character of service is that using a pantograph arrangement of links carrying contacts, thus giving a break in a vertical plane. Both of these types of switch have for years been in successful operation under all conditions of load. They have a weakness common to all oil switches, in that when operated under heavy short circuits they will at times throw oil out of the container.

Outdoor oil switches, either automatic or non-automatic, are being used very generally for branch lines, or for sectionalizing trunk lines. For economic reasons the automatic switches are 
very often operated by means of a solenoid placed directly in the main line. Such an arrangement does away with the use of current transformers, but has the objection that the connection from the movable plunger to the relay, or trip, must stand the entire voltage from line to ground.

As the sensitiveness of the trip is, to a considerable extent, dependent upon the weight of the moving parts, the importance of keeping this weight down to a minimum is apparent. Welltreated rods of sufficient length have been used to make the connection from the plunger to the trip, or relay, but they have not been entirely satisfactory, because sooner or later the leakage burns them off.

Transformer designs have more than kept pace with the art of long-distance transmission at high voltages, and it is now possible to get satisfactory apparatus for any voltage that can be handled on the lines.

One thing, however, that some manufacturers have failed to give proper attention to is that of supporting the windings to prevent injury or distortion due to mechanical strains set up when short circuits occur. In units of large capacities and high voltages, the coils are generally built of strap copper, using one turn per layer, these turns being separated by one or more thicknesses of insulating material. Obviously, with such a construction, the turns will be easily displaced, unless they are well supported on both sides.

A number of failures have recently occurred where straight vertical separating strips have been used in assembling the coils, thus leaving the turns between these separating strips unsupported throughout their entire length, and allowing them to be displaced when short circuits came on. Shorter strips placed diagonally across the coils, or wave-shaped strips, which will allow a free circulation of oil, will entirely overcome this trouble.

\section{APPENDIX IV-SWITCHING}

\section{BY G. FACCIOLI}

Switching produces, in general, an abrupt change in the value of the electromotive force and of the current of the circuit, or of either of these quantities, and therefore it produces a sudden change in the amount of energy stored in the circuit, with the result that oscillations are produced.

The severity of these oscillations depends on the difference be- 
tween the running conditions before and after the switching is done. For instance, if a dead line at zero potential is suddenly connected to an alternating-current generator, the oscillation produced will be most severe when the switch makes the connection at the instant at which the electromotive force has its maximum value. Likewise, if a short-circuited line is disconnected from an alternating-current generator, the oscillation is most severe when the circuit is broken at the instant at which the current passes through its maximum value.

The oscillations are of two kinds: They may occur between inductance massed at one point of the circuit, and capacity massed at another point of the circuit, as, for instance, when a dead line which acts practically as a condenser is connected to a generator which acts practically as an inductance, or when a line (capacity) connected at one end to a step-down transformer (inductance) is disconnected from the generating system.

They may also occur between the distributed inductance and capacity of a part of the circuit, as, for instance, when a line is disconnected from a generator and the energy stored in the line gradually dies out, changing from electromagnetic energy stored in the distributed inductance of the line, to electrostatic energy stored in the distributed capacity of the line and vice versa, or when an unloaded step-down transformer is disconnected from the line, its windings acting similarly to a line.

These oscillations do not, in general, constitute a great danger to the circuit if the contact in the switch is made once, positively, for every switching operation.

However, if each switching operation is accompanied by arcs, so that the circuit is repeatedly closed and opened, then the pressure rises may become dangerous, and destructive cumulative oscillations may be set up in the apparatus. Furthermore, at the instant at which contact is made, traveling waves are sent out from the point of switching along the line in both directions. These traveling waves with steep fronts follow, naturally, the well-known rules of reflection and refraction, and whenever they strike a localized oscillatory circuit, they excite in it oscillations at its natural period.

For instance, if a dead line is suddenly connected to a live line having the same constants, a "wave of charge," equal in value to one-half of the potential of the live line, starts along the dead line from the switching point. If the dead line is open at the far end, the "wave of charge" is reflected back at double 
potential, etc., etc. At the same time a "wave of discharge" starts along the live line from the switching point with a value equal to one-half of the original voltage of this line. If the live line is connected at its origin to transformers, this "wave of discharge" is reflected back with double voltage and may excite local oscillations in the transformer windings or in the circuits of the power house, etc., etc.

These traveling waves are a source of danger and obviously the danger is increased when sparking and arcing occur in the switch.

It is seen from the above that high-tension switching, which has lately gained so much importance in the art, should be done very judiciously and only when necessary, unless special precautions are taken to avoid the disturbances resulting therefrom.

As a rule, low-tension switching is preferable, as this avoids steep wave front phenomena.

For instance, in energizing a line, it is preferable to connect the dead line to the dead step-up transformer and then connect, by low-tension switches, the line and transformer to the generator, rather than connecting the transformer alone to the generator and then switching the line onto the high-tension winding of the transformer. Of course, in this case it would be still better to connect the line and the step-up transformer and the generator together while the whole system is dead and then bring it up gradually to full potential by the excitation of the generator.

Fuses act similarly to switches, except that the former open under load, while switches are, as a rule, operated at approximately no-load. The sudden interruption of large amounts of current results in considerable over-tensions, and this is the danger that usually accompanies the blowing of fuses. 